\title{
Review Article \\ Pediatric Resuscitation: Outcome Effects of Location, Intervention, and Duration
}

\author{
John P. Scott, Lindsey Loveland Baptist, and Richard J. Berens \\ Medical College of Wisconsin, Children's Hospital of Wisconsin, Milwaukee, WI 53226, USA \\ Correspondence should be addressed to Richard J. Berens; rberens@chw.org
}

Received 24 September 2014; Accepted 24 December 2014

Academic Editor: Ming-Hwang Shyr

Copyright (C) 2015 John P. Scott et al. This is an open access article distributed under the Creative Commons Attribution License, which permits unrestricted use, distribution, and reproduction in any medium, provided the original work is properly cited.

\begin{abstract}
Cardiopulmonary resuscitation (CPR) is performed in order to restore oxygen delivery and prevent multiorgan system failure and death. Prompt initiation of CPR with appropriate medical or surgical therapy may shorten arrest duration before irreversible organ injury occurs. The brain is most susceptible to irreversible anoxic injury. Survival data suggests that children are more likely than adults to survive and have good neurologic outcomes following cardiac arrest. In this review of pediatric resuscitation, we discuss important predictors of postarrest outcomes as well as advances in resuscitation science focusing on the critical importance of oxygen delivery during periarrest care.
\end{abstract}

\section{Introduction}

Oxygen delivery $\left(\mathrm{DO}_{2}\right)$ is the product of cardiac output $(\mathrm{CO})$ and arterial oxygen content $\left(\mathrm{CaO}_{2}\right)$ as $\mathrm{DO}_{2}=\mathrm{CO} \times \mathrm{CaO}_{2}$. Cardiac arrest results in cessation of oxygen delivery and development of global oxygen debt. When oxygen delivery is not restored, multiorgan organ failure and death ensue [1]. Cardiopulmonary resuscitation (CPR) is performed in order to restore oxygen delivery and prevent cell death. When the etiology of cardiorespiratory failure is clear and recognizable, expedient initiation of CPR with appropriate medical or surgical therapy may shorten arrest duration before irreversible organ injury occurs. The brain is most susceptible to irreversible anoxic injury. Survival data suggests that the potential to rescue following cardiac arrest is greatest in children $[2,3]$.

According to the American Heart Association (AHA), the first use of mouth-to-mouth resuscitation occurred in the mid-1700s. The first documented chest compressions were performed in the early 1900s. Leonard Cobb organized the world's first mass citizen training in CPR in Seattle, Washington called Medic 2. More than 100,000 people were trained during the first two years of the program. While most early studies focused on adult resuscitation, attention to pediatric resuscitation has increased dramatically in the last quarter century.
Early statistics suggest that most pediatric arrest victims either die or have poor neurologic outcomes [2-11]. Efforts to improve outcomes are directed at augmenting oxygen delivery and mitigating oxygen debt during all phases of periarrest management. In this review of pediatric resuscitation, we discuss important predictors of postarrest outcomes as well as advances in resuscitation science focusing on the critical importance of normalization of oxygen delivery during periarrest care.

\section{Predictors of Outcome}

2.1. Location of Arrest. Location of arrest is highly predictive of morbidity and mortality. Cardiac arrests are broadly classified as in hospital (IHCA) or out of hospital of hospital (OHCA) cardiac arrests. Current life support algorithms are designed to help lay providers and healthcare professionals resuscitate arrest victims in any setting.

2.1.1. Out of Hospital Cardiac Arrest (OHCA). According to the 2013 AHA Heart Disease and Stroke Statistics, approximately 360,000 patients suffer OHCA annually in the United States. In a comprehensive review of OHCA in children, Atkins et al. cited an incidence of 8 per 100,000 person years. The Resuscitation Outcomes Consortium (ROC) analyzed 
pediatric cardiac arrest according to age subgroups (less than 1 year, 1 to 11 years, and 12 to 19 years) [3]. When stratified for age, infants OHCA rates (72 per 100,000 person years) were comparable to adult rates (127 per 100,000 person years). The incidence of OHCA in children aged 1-19 years is significantly less [3].

The ROC study documented overall post-OHCA survival of $6 \%$. Infants and adults have the lowest survival rates of $3 \%$ and $6 \%$, respectively. Children beyond infancy experience higher survival rates (9\%) [3]. Most pediatric OHCA occur in males $(56 \%)$ under one year of age $(62 \%)$. Few pediatric arrests are witnessed (31\%) or receive bystander CPR (30\%) administered. Factors that seemed to favor hospital discharge include having a witnessed arrest with bystander CPR of short duration prior to return of spontaneous circulation (ROSC) $[12,13]$.

2.1.2. In Hospital Cardiac Arrest (IHCA). IHCAs typically occur in two locations, the intensive care unit (ICU) and operating room (OR). Compared to OHCA, survival after IHCA is higher for all ages. Respiratory failure is the most common etiology of pediatric IHCA [4]. The American Medical Association (AMA) National Registry of Cardiopulmonary Resuscitation (NRCPR) study of pediatric IHCA found that most arrests are witnessed and occur in the ICU [2]. More than one-half of children achieve ROSC, onequarter survive to discharge, and more than one-half of survivors experience good neurologic outcomes [2].

Initial studies of pediatric IHCA reported survival rates comparable to OHCA [14]. Importantly, post-IHCA survival has improved significantly over the past 2 decades [11]. A longitudinal study of pediatric IHCA performed as part of The Get With The Guidelines (GWTG) Registry analyzed 1031 pediatric arrests in 12 hospitals from 2000 to 2009. Risk adjusted survival rates increased significantly from 2000 to 2009 (14\% versus 43\%) without other associated changes in other adverse outcomes or neurologic disability [11]. Factors associated with improved survival to discharge and good neurologic outcome include short duration of arrest (less than 20 minutes) and cardiac surgical disease $[9,10]$. Newborns and infants were shown to have better survival following cardiac arrest in the ICU [15]. Systolic hypotension and lactic acidosis following IHCA were associated with poor survival and neurological prognosis [16, 17].

2.2. Perioperative Cardiac Arrest. Perioperative cardiac arrest (POCA) is an outlier with significantly higher survival than other forms of IHCA and OHCA. These arrests typically occur in the operating room or recovery room. Common etiologies of POCA arrest include volatile and local anesthetic toxicity, hypovolemia, airway emergencies, venous air embolism, and anaphylaxis [18, 19].

The Pediatric Cardiac Arrest Registry study performed from 1994 to 1997 concluded that intraoperative arrests were frequently medication related and commonly associated with the volatile anesthetic agent Halothane [18]. Subsequent analyses suggest that medication related arrests have decreased over time. Volatile anesthetic associated cardiac arrest has declined with the reduction of halothane use [19]. A recent quality improvement database review of more than 217,000 anesthetics documented 160 cardiac arrests within a $24 \mathrm{~h}$ perioperative period. Approximately 25 percent of these arrests were directly attributed to anesthesia. Fourteen deaths were attributed to the anesthetic (an incidence of 0.6 per 10,000 anesthetics) [20]. Additionally, 23 of the 160 arrests were found to have anesthesia as a contributing factor (incidence of 1.1 per 10,000). Airway complications resulted in over 60 percent of the anesthesia related perioperative arrests with a mortality rate of nearly 30 percent [20].

Children with congenital heart disease who suffer POCA are at high risk of mortality based on severity of illness [21]. Following POCA, one-third of children with congenital heart disease die versus one-quarter of children without cardiac disease. Children with single ventricle physiology have the highest incidence of POCA, while those with cardiomyopathies experience the highest mortality [21]. Other risk factors include infancy (age less than 1 year), high ASA status, emergency surgery, and preexisting hematologic, oncologic, immunologic, genetic, or metabolic disease [7, 18, 22, 23].

While anesthetic agents are frequently implicated in POCA, it is important to remember that anesthetic effect may contribute to more favorable outcomes following ROSC. Most anesthetics decrease tissue oxygen metabolism resulting in lower $\mathrm{DO}_{2}$ requirements, which may be protective after abrupt reductions in oxygen delivery as occurs in arrest scenarios [24].

2.3. Initial Cardiac Rhythm. The initial documented cardiac rhythm following cardiac arrest is a major predictor of survival [2]. Postarrest cardiac rhythms are divided into three subgroups: malignant ventricular dysrhythmias (ventricular fibrillation (VF) or ventricular tachycardia (VT)), asystole, and PEA. Arrhythmia incidence differs between pediatric and adult arrests [2]. Asystole is the predominant presenting rhythm in children followed by PEA [4]. Ventricular dysrhythmias (VF/VT) are least prevalent. However, ventricular dysrhythmias occur more commonly in the setting of IHCA, occurring in up to $25 \%$ of children $[2,5]$.

The timing of malignant ventricular dysrhythmia generation is predictive of postarrest survival. Primary VT/VF is associated with more than $30 \%$ survival to discharge [5]. Early defibrillation of VF/VT is associated with high rates of ROSC and favorable outcomes [25]. Secondary development of VF/VT has lower survival than primary VF/VT, pulseless electrical activity (PEA), or asystole [5]. Irrespective of rhythm survival to discharge, ROSC, and neurological recovery are all higher in children [2].

2.4. Compression Duration. The relationship of compression duration to survival has been studied extensively $[2,5,7$, 10, 26-28]. Early studies of pediatric resuscitation concluded that patients who received compressions for more than $>20$ minutes were irretrievable [26]. However, with improved pediatric arrest outcomes this conclusion has been refuted [10]. The impact of compression duration on pediatric arrest outcomes was evaluated in a multicenter study of 267 patients 


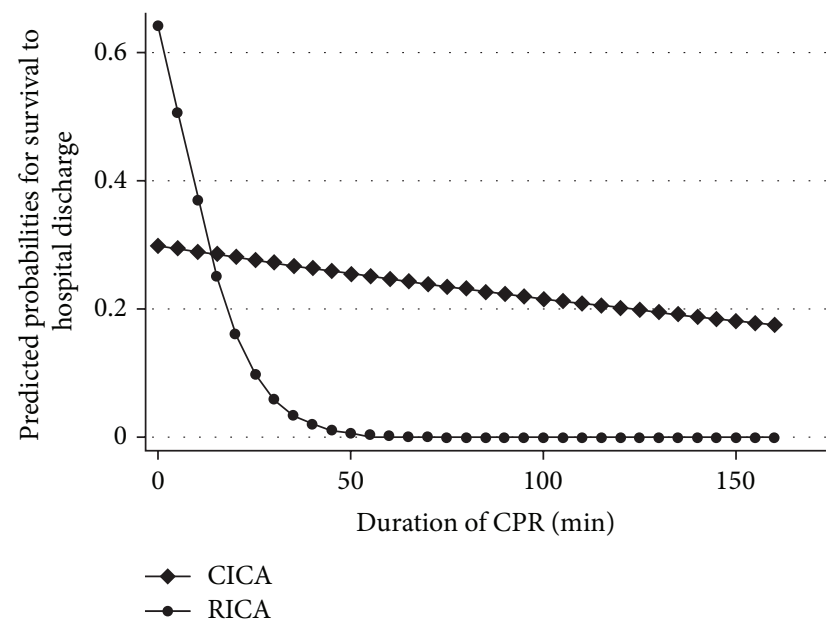

Figure 1: Cardiac versus Respiratory Induced Cardiac Arrest. The probability of survival with increasing CPR duration based on the logistic regression analysis stratified by CICA and RICA (with permission: Paediatr Anaesth. 2011 Aug; 21 (8):834-40).

from 6 hospitals [28] (Figure 1). Children were stratified according to etiology of arrest (respiratory versus cardiac). In setting of respiratory failure induced cardiac arrest survival declined exponentially after 15 minutes of duration, but after cardiac failure induced cardiac arrest, many children survived with good neurologic outcomes with compression duration of up to one hour [28]. Matos et al. divided compression duration into three categories $(1-15,16-35$, and greater than 35 minutes) and concluded that mortality and neurological disability varied directly with compression duration yet still observed $16.5 \%$ survival and favorable neurologic recovery with compressions greater than 35 minutes. In this study, cardiac surgical patients had the highest survival rate, more so in those receiving extracorporeal mechanical support (ECMO) rescue. Traumatic arrest patients had the lowest survival rates [10].

\section{Advances in Resuscitation}

3.1. Prearrest Interventions. Enhanced identification of evolving oxygen debt in the prearrest setting allows for goal directed interventions prior to arrest development. Multifocal efforts to aid provider management of at risk children include early warning system scores, medical emergency teams, and advanced noninvasive monitoring.

3.1.1. Early Warning System Scores. Standardized severity of illness scoring systems have been developed for early identification of at risk patients. Any effective scoring system must be reliable and reproducible. When critical abnormalities are identified there must also be an appropriate response [29]. The efficacy of any early warning system score is dependent on observers who are able to reliably assess and measure individual components of the score and initiate proper interventions [29].

The Pediatric Early Warning System (PEWS) Score incorporates heart rate, blood pressure, capillary refill time, respiratory rate, oxygen saturation, and need for supplemental oxygen [30]. Parshuram et al. conducted a multicenter case control study of bedside PEWS Scores in more than 2000 children admitted to 4 hospitals in Canada and the UK. This study revealed a temporal association between escalation of bedside PEWS Scores and unplanned ICU admission and code blue events [31].

Many institutions, including ours, routinely use early warning system scores in an effort to reduce cardiac and respiratory arrests. Unfortunately, there remains a lack of consensus on an accepted pediatric scoring system. Currently, at least nine scoring systems are in use throughout North America, Europe, and Australia [29]. Critics of standardized severity of illness scores cite high false positive rates as well as other methodological flaws $[29,32]$.

3.1.2. Medical Emergency Teams. Medical emergency teams (METs) or rapid response teams (RRTs) were developed for the urgent assessment of at risk patients. These teams may function as the efferent response to the critical afferent early warning score signal. MET models were initially developed for adult hospitals. Adult studies report reduced code blue incidence and in hospital mortality $[33,34]$. This data has prompted pediatric centers to develop METs.

There is growing evidence that pediatric METs are effective in reducing clinical deterioration of at risk children resulting in lower code blue rates and in hospital mortality [35-38]. A meta-analysis of available pediatric METs revealed reduced in hospital mortality and cardiac arrest outside of the ICU [39]. These conclusions were bolstered by a Canadian multicenter pediatric MET study that showed lower PICU mortality [40]. Unplanned ICU admissions may increase following MET implementation [37]. Many METs function as separate entities from code blue teams limiting resource overextension in a large tertiary care pediatric hospitals. Simulation based MET training exercises have been linked to improved team performance and outcomes [41].

3.1.3. Advanced Monitoring. Excluding respiratory failure, shock is the most common cause of pediatric cardiac arrest $[4,42]$. In biochemical shock, inadequate $\mathrm{DO}_{2}$ results in oxygen debt and anaerobic metabolism [1, 43]. The initial evaluation of a child with suspected shock includes an assessment of indices of perfusion including heart rate, blood pressure, capillary refill time, urine output, and mental status. These parameters do not correlate well with the severity of circulatory insufficiency or oxygen debt [42-47]. Modern goal directed shock resuscitation models incorporate systemic venous oxygen saturation $\left(\mathrm{SvO}_{2}\right)$ measurement as a surrogate for oxygen delivery based on the Fick equation as $\mathrm{SvO}_{2}=\mathrm{SaO}_{2}-\mathrm{VO}_{2} / \mathrm{DO}_{2}[44,46]$. However, $\mathrm{SvO}_{2}$ monitoring requires central venous access, which may not be feasible in many prearrest environments (i.e., hospital wards).

Near infrared spectroscopy (NIRS) represents an important method of assessing regional oxygen delivery in completely noninvasive manner. The NIRS derived regional oxygen saturation $\left(\mathrm{rSO}_{2}\right)$ reflects tissue venous saturation. When compared with the arterial oxygen saturation this allows for 
an estimation of regional oxygen metabolism based on a variation of the Fick relationship $\left(\mathrm{rSO}_{2}=\mathrm{SaO}_{2}-\mathrm{VO}_{2} / \mathrm{DO}_{2}\right)$ $[45,47]$.

Two-site cerebral and somatic NIRS monitoring enables a more comprehensive assessment of $\mathrm{SvO}_{2}$ and systemic $\mathrm{DO}_{2}$. Two-site cerebral and somatic NIRS monitoring measures regional oxygen delivery to the autoregulated cerebral and sympathetically mediated renal-somatic circulations. Under normal conditions, the renal somatic saturation $\left(\mathrm{rSO}_{2} \mathrm{~S}\right)$ is approximately 10 percent greater than the cerebral saturation $\left(\mathrm{rSO}_{2} \mathrm{C}\right)$ [48]. A reduction in this somatic to cerebral difference $\left(\Delta \mathrm{rSO}_{2} \mathrm{SC}\right)$ is associated with the development of somatic hypoperfusion and anaerobic metabolism [49].

Sympathetically mediated vasoconstriction with progressive shock results in renal hypoperfusion, reduced somatic regional saturation, and eventual loss of pulsatility. NIRS devices perform well in shock states when blood flow is nonpulsatile as occurs with profound tissue hypoperfusion. This lack of reliance of pulsatile flow makes NIRS monitoring ideal in periarrest situations. Using two site NIRS monitoring, earlier detection and goal directed therapy of shock is possible [49-52].

3.1.4. CPR Guidelines. The AHA recommendations for single and multiple provider CPR have evolved over time. The 2010 guidelines represented a philosophical shift to circulation-based resuscitation [53]. Historically, CPR proceeded according to the $\mathrm{ABC}$ sequence of airway-breathingcirculation (ABC). The 2010 recommendations were modified to circulation-airway-breathing (CAB) with compressions preceding other interventions. In fact, compression only CPR is recommended for single provider CPR of an adult as most adult arrests are primarily cardiac in origin, and generation of adequate coronary perfusion pressure is essential for ROSC [53-55]. Compression first and compression only CPR emphasize restoration of cardiac output (CO) to augment coronary perfusion pressure and coronary $\mathrm{DO}_{2}$ to achieve ROSC [53].

While the AHA recommends compression only CPR for single providers during adult arrests, this is not true for pediatric CPR. Most pediatric cardiac arrests are asphyxial in nature. The reduction of arterial oxygen content of blood during the asphyxial period preceding arrest contributes to $\mathrm{DO}_{2}$ limitation and increasing cellular oxygen debt prior to cessation of cardiac output. Thus, augmentation of the arterial oxygen content with assisted ventilation is critical following asphyxial pediatric arrest. There is data that suggests restoration of oxygenation and ventilation via conventional CPR following asphyxial arrest is associated with improved outcomes when compared to compression only CPR in pediatric OHCA [56]. This is further supported by animal studies of asphyxial cardiac arrest [57-60].

IHCA resuscitations generally involve healthcare providers performing multiprovider CPR. This lends itself to the performance of multiple tasks in parallel and the AHA acknowledges that there may be variation in the sequence which airway breathing and circulation are supported during in hospital multiprovider CPR [53]. The ability to simultaneously augment both cardiac output and arterial oxygen content results in cumulative improvement in oxygen delivery to ischemic tissues, which may contribute to improved IHCA outcomes.

3.1.5. Compression Quality. Appropriate compression rate and depth is critical to performance of high quality. The 2005 AHA/ILCOR guidelines increased the compression to ventilation ratio for single person CPR from $15: 2$ to $30: 2$ as higher compression to ventilation ratios have been shown to increase coronary perfusion pressure, diastolic blood pressure, and coronary $\mathrm{DO}_{2}[53,61,62]$. Hemodynamic goal directed CPR targeting coronary perfusion pressure of $20 \mathrm{mmHg}$ has been shown to improve survival in porcine arrest models [63].

The current 2010 guidelines recommend a minimum rate of 100 compressions per minute and minimum depth of compression of $50 \mathrm{~mm}$ [53]. These recommendations replaced the 2005 recommendations of $38 \mathrm{~mm}$ compression depth. While the previous target has been shown to generate a systolic blood pressure of at least $80 \mathrm{mmHg}$ and diastolic blood pressure of at least $30 \mathrm{mmHg}$, compression depth greater than $51 \mathrm{~mm}$ during CPR is associated with greater 24hour survival rates [63]. However, a major criticism of the 2010 recommendations is difficulty achieving the appropriate compression rate and depth during actual code events [63]. Rolling bedside resuscitation refresher courses utilizing compression quality monitoring are ongoing [64].

3.1.6. Resuscitative Medications. The most commonly administered vasoactive medication following cardiac arrest is epinephrine. Epinephrine increases coronary perfusion pressure, which is essential to achieve ROSC. However, high dose $(>100 \mathrm{mcg} / \mathrm{kg}$ ) epinephrine inhibits oxygen transport resulting in reduced $\mathrm{DO}_{2}$ [65]. Above this threshold, the cumulative epinephrine dose is directly related with the level of impairment of $\mathrm{DO}_{2}$ [65]. Both high dose $(\geq 100 \mathrm{mcg} / \mathrm{kg})$ and standard dose $(10 \mathrm{mcg} / \mathrm{kg})$ regimens of epinephrine have been utilized during pediatric code events. Studies evaluating the use of high dose epinephrine have failed to demonstrate improved survival or neurologic outcomes. Animal studies comparing $200 \mathrm{mcg} / \mathrm{kg}$ versus $20 \mathrm{mcg} / \mathrm{kg}$ doses during resuscitation after cardiac arrest reveal increased mortality with high dose epinephrine $[66,67]$.

In a randomized control trial of pediatric IHCA, Perondi et al. compared $100 \mathrm{mcg} / \mathrm{kg}$ and $10 \mathrm{mcg} / \mathrm{kg}$ dose epinephrine and demonstrated reduced survival at 24 hours after arrest with high dose epinephrine [68]. Retrospective analyses of pediatric IHCA and OHCA pediatric arrest have failed to show a benefit to high dose epinephrine $[69,70]$. Similarly, less frequent epinephrine dosing following cardiac arrest has been linked to improved survival when compared to recommended dosing interval of every 3-5 minutes [71].

Bicarbonate and calcium administration during neonatal and pediatric resuscitations remain a source of controversy. Neither medication has been shown to be associated with improved survival following cardiac arrest. The most recent review of pediatric resuscitations from the GWTG Registry linked that both medications to reduced survival 
[42]. According GWTG and AHA guidelines, the only clear indications for calcium administration are hyperkalemia, hypocalcemia, or calcium channel blocker toxicity [42, 72]. Calcium administration has been linked to decreased odds of survival and worse outcomes in pediatric $\mathrm{VF} / \mathrm{VT}$ arrest $[5,73]$. Bicarbonate administration is only indicated during arrest secondary to hyperkalemia or toxin ingestions such as tricyclic antidepressants $[42,72]$.

3.1.7. Mechanical Support. Extracorporeal membrane oxygenation (ECMO) support may be utilized for refractory circulatory or respiratory failure [74]. All mechanical support devices consist of a pump and an oxygenator allowing for augmentation of cardiac output and arterial oxygen content. There are veno-veno (VV) and venoarterial (VA) modalities of ECMO. Veno-Venous ECMO is indicated for respiratory failure with preserved myocardial pump function, while VA ECMO is required for combined cardiorespiratory failure. Cannulation for mechanical support is typically performed in either the intensive care unit or in the operating room. Many pediatric centers, including ours, have rapid response ECMO teams in place so to shorten arrest duration when the need for mechanical support has been identified [75]. Acceptable survival and neurologic outcomes may be achieved following ECMO rescue, even in the setting of prolonged resuscitation, especially children with preexisting cardiac disease [76-78]. Survival in children with cardiac disease who require ECMO rescue may approach $50 \%$ [79].

\subsection{Postresuscitation Interventions}

3.2.1. Therapeutic Hypothermia. Neuronal cell death following cardiac arrest occurs within minutes. Secondary injury develops during the ischemia reperfusion phase and evolves in the days following the injury. Mechanisms involved in postreperfusion secondary injury include cytotoxic cerebral edema, seizures, excitotoxicity, free radical production, and neuronal apoptosis [80]. The severity of these destructive processes determines whether at risk neurons within the ischemic penumbra survive. Therapeutic hypothermia (TH) has been shown to inhibit many of these processes. Induction of hypothermia also serves to optimize cerebral oxygen economy by reducing cerebral metabolic rate and cerebral oxygen consumption [80, 81]. Methods utilized include surface cooling (blankets, ice packs, pads, and immersion) and core cooling.

The patient populations with the most published data supporting therapeutic hypothermia are infants with hypoxic ischemic encephalopathy (HIE) and adults with cardiac arrest. Cochrane Database Reviews of neonates with HIE have reduced mortality and neurologic disability at 18 months when treated with $\mathrm{TH}$ [82]. Similarly, TH is also associated with improved neurologic outcomes in adults following OHCA [83-88]. There is insufficient data at this time regarding the efficacy of $\mathrm{TH}$ in pediatric patients following cardiac arrest [89].

Whether or not $\mathrm{TH}$ is utilized following cardiac arrest, it is clear that fever following arrest is associated with worse outcome [90-92]. Current recommendations include avoidance of fever and aggressive treatment of hyperthermia post cardiac arrest given this linkage to poor outcomes [93].

3.2.2. Electroencephalogram Monitoring. Cerebral hypoxic ischemic injuries lower the seizure threshold in children following cardiac arrest. Untreated seizures increase cerebral oxygen consumption and exacerbate secondary brain injury. Continuous electroencephalogram (EEG) monitoring is useful to detect epileptiform activity in children who may have subclinical seizures or who may be under neuromuscular blockade. Studies of EEG monitoring in children report a high incidence of postarrest seizure activity and status epilepticus [94]. Seizures in critically ill children are predictive of decreased survival and worse neurologic outcomes [95]. Continuous EEG monitoring may also provide important prognostic information as reduced EEG activity and reactivity portend poor neurological outcomes [96].

\section{Summary}

While pediatric arrest outcomes remain suboptimal, maintaining effective oxygen economy at each phase of care may improve survival and neurological status. Arrest location and initial cardiac rhythm remain significant predictors of mortality. Witnessed, out-of-hospital arrests followed by prompt by-passer intervention improve survival to hospital discharge. Early warning systems, medical emergency teams, and advanced noninvasive monitoring improve identification of at risk patients in the in-hospital prearrest setting. CPR guidelines have continued to evolve, with current focus on compression quality and pharmacotherapy. Finally, in the postarrest setting, favorable cerebral oxygen metabolism is maintained to optimize neurologic outcome. It is imperative that providers focus on all aspects of periarrest care in order to achieve favorable neurologic recovery and survival.

\section{Conflict of Interests}

The authors declare that there is no conflict of interests regarding the publication of this paper.

\section{References}

[1] W. C. Shoemaker, P. L. Appel, and H. B. Kram, "Role of oxygen debt in the development of organ failure sepsis, and death in high-risk surgical patients," Chest, vol. 102, no. 1, pp. 208-215, 1992.

[2] V. M. Nadkarni, G. L. Larkin, M. A. Peberdy et al., "First documented rhythm and clinical outcome from in-hospital cardiac arrest among children and adults," The Journal of the American Medical Association, vol. 295, no. 1, pp. 50-57, 2006.

[3] D. L. Atkins, S. Everson-Stewart, G. K. Sears et al., "Epidemiology and outcomes from out-of-hospital cardiac arrest in children: the resuscitation outcomes consortium epistrycardiac arrest," Circulation, vol. 119, no. 11, pp. 1484-1491, 2009.

[4] A. G. Reis, V. Nadkarni, M. B. Perondi, S. Grisi, and R. A. Berg, "A prospective investigation into the epidemiology of in-hospital pediatric cardiopulmonary resuscitation using the 
international Utstein reporting style," Pediatrics, vol. 109, no. 2 I, pp. 200-209, 2002.

[5] R. A. Samson, V. M. Nadkarni, P. A. Meaney, S. M. Carey, M. D. Berg, and R. A. Berg, "Outcomes of in-hospital ventricular fibrillation in children," The New England Journal of Medicine, vol. 354, no. 22, pp. 2328-2339, 2006.

[6] J. Tibballs and S. Kinney, "A prospective study of outcome of inpatient paediatric cardiopulmonary arrest," Resuscitation, vol. 71, no. 3, pp. 310-318, 2006.

[7] K. L. Meert, A. Donaldson, V. M. Nadkarni et al., "Multicenter cohort study of in-hospital pediatric cardiac arrest," Pediatric Critical Care Medicine, vol. 10, no. 5, pp. 544-615, 2009.

[8] F. W. Moler, A. E. Donaldson, K. Meert et al., "Multicenter cohort study of out-of-hospital pediatric cardiac arrest," Critical Care Medicine, vol. 39, no. 1, pp. 141-149, 2011.

[9] L. Ortmann, P. Prodhan, J. Gossett et al., "Outcomes after inhospital cardiac arrest in children with cardiac disease: a report from get with the guidelines-resuscitation," Circulation, vol. 124, no. 21, pp. 2329-2337, 2011.

[10] R. I. Matos, R. S. Watson, V. M. Nadkarni et al., "Duration of cardiopulmonary resuscitation and illness category impact survival and neurologic outcomes for in-hospital pediatric cardiac arrests," Circulation, vol. 127, no. 4, pp. 442-451, 2013.

[11] S. Girotra, J. A. Spertus, Y. Li, R. A. Berg, V. M. Nadkarni, and P. S. Chan, "Survival trends in pediatric in-hospital cardiac arrests an analysis from get with the guidelines-resuscitation," Circulation: Cardiovascular Quality and Outcomes, vol. 6, no. 1, pp. 42-49, 2013.

[12] M. Kuisma, P. Suominen, and R. Korpela, "Paediatric out-ofhospital cardiac arrests-epidemiology and outcome," Resuscitation, vol. 30, no. 2, pp. 141-150, 1995.

[13] M. B. Schindler, D. Bohn, P. N. Cox et al., "Outcome of outof-hospital cardiac or respiratory arrest in children," The New England Journal of Medicine, vol. 335, no. 20, pp. 1473-1479, 1996.

[14] A. Torres Jr., C. B. Pickert, J. Firestone, W. M. Walker, and D. H. Fiser, "Long-term functional outcome of inpatient pediatric cardiopulmonary resuscitation," Pediatric Emergency Care, vol. 13, no. 6, pp. 369-373, 1997.

[15] P. A. Meaney, V. M. Nadkarni, E. F. Cook et al., "Higher survival rates among younger patients after pediatric intensive care unit cardiac arrests," Pediatrics, vol. 118, no. 6, pp. 2424-2433, 2006.

[16] A. A. Topjian, B. French, R. M. Sutton et al., "Early postresuscitation hypotension is associated with increased mortality following pediatric cardiac arrest," Critical Care Medicine, vol. 42, no. 6, pp. 1518-1523, 2014.

[17] A. A. Topjian, A. E. Clark, T. C. Casper et al., "Early lactate elevations following resuscitation from pediatric cardiac arrest are associated with increased mortality," Pediatric Critical Care Medicine, vol. 14, no. 8, pp. e380-e387, 2013.

[18] J. P. Morray, J. M. Geiduschek, C. Ramamoorthy et al., "Anesthesia-related cardiac arrest in children: initial findings of the pediatric perioperative cardiac arrest (POCA) registry," Anesthesiology, vol. 93, no. 1, pp. 6-14, 2000.

[19] S. M. Bhananker, C. Ramamoorthy, J. M. Geiduschek et al., "Anesthesia-related cardiac arrest in children: update from the pediatric perioperative cardiac arrest registry," Anesthesia and Analgesia, vol. 105, no. 2, pp. 344-350, 2007.

[20] S. J. Ellis, M. C. Newland, J. A. Simonson et al., "Anesthesiarelated cardiac arrest," Anesthesiology, vol. 120, no. 4, pp. 829838, 2014.
[21] C. Ramamoorthy, C. M. Haberkern, S. M. Bhananker et al., "Anesthesia-related cardiac arrest in children with heart disease: data from the pediatric perioperative cardiac arrest (POCA) registry," Anesthesia \& Analgesia, vol. 110, no. 5, pp. 1376-1382, 2010.

[22] L. G. Braz, J. R. G. Braz, N. S. P. Módolo, P. do Nascimento Jr., B. A. M. Brushi, and L. R. de Carvalho, "Perioperative cardiac arrest and its mortality in children. A 9-year survey in a Brazilian tertiary teaching hospital," Paediatric Anaesthesia, vol. 16, no. 8, pp. 860-866, 2006.

[23] N. Bharti, Y. K. Batra, and H. Kaur, "Paediatric perioperative cardiac arrest and its mortality: database of a 60 -month period from a tertiary care paediatric centre," European Journal of Anaesthesiology, vol. 26, no. 6, pp. 490-495, 2009.

[24] S. A. McLellan and T. S. Walsh, "Oxygen delivery and haemoglobin," Continuing Education in Anaesthesia, Critical Care \& Pain, vol. 4, no. 4, pp. 123-126, 2004.

[25] J. S. Strobel, B. H. Kenknight, D. L. Rollins, W. M. Smith, and R. E. Ideker, "The effects of ventricular fibrillation duration and site of initiation on the defibrillation threshold during early ventricular fibrillation," Journal of the American College of Cardiology, vol. 32, no. 2, pp. 521-527, 1998.

[26] A. Zaritsky, V. Nadkarni, P. Getson, and K. Kuehl, "CPR in children," Annals of Emergency Medicine, vol. 16, no. 10, pp.11071111, 1987.

[27] V. Nadkarni, M. F. Hazinski, D. Zideman et al., "Paediatric life support. An advisory statement by the Paediatric Life Support Working Group of the International Liaison Committee on Resuscitation," Resuscitation, vol. 34, no. 2, pp. 115-127, 1997.

[28] R. J. Berens, L. D. Cassidy, J. Matchey et al., "Probability of survival based on etiology of cardiopulmonary arrest in pediatric patients," Paediatric Anaesthesia, vol. 21, no. 8, pp. 834-840, 2011.

[29] G. Pearson and H. Duncan, "Early warning systems for identifying sick children," Paediatrics and Child Health, vol. 21, no. 5, pp. 230-233, 2011.

[30] H. Duncan, J. Hutchison, and C. S. Parshuram, "The pediatric early warning system score: a severity of illness score to predict urgent medical need in hospitalized children," Journal of Critical Care, vol. 21, no. 3, pp. 271-278, 2006.

[31] C. S. Parshuram, H. P. Duncan, A. R. Joffe et al., "Multicentre validation of the bedside paediatric early warning system score: a severity of illness score to detect evolving critical illness in hospitalised children," Critical Care, vol. 15, no. 4, article R184, 2011.

[32] J. Tibballs and S. Kinney, "Evaluation of a paediatric early warning tool-Claims unsubstantiated," Intensive and Critical Care Nursing, vol. 22, no. 6, pp. 315-316, 2006.

[33] G. Salvatierra, R. C. Bindler, C. Corbett, J. Roll, and K. B. Daratha, "Rapid response team implementation and in-hospital mortality," Critical Care Medicine, vol. 42, no. 9, pp. 2001-2006, 2014.

[34] S. Al-Qahtani, H. M. Al-Dorzi, H. M. Tamim et al., "Impact of an intensivist-led multidisciplinary extended rapid response team on hospital-wide cardiopulmonary arrests and mortality," Critical Care Medicine, vol. 41, no. 2, pp. 506-517, 2013.

[35] R. J. Brilli, R. Gibson, J. W. Luria et al., "Implementation of a medical emergency team in a large pediatric teaching hospital prevents respiratory and cardiopulmonary arrests outside the intensive care unit," Pediatric Critical Care Medicine, vol. 8, no. 3, pp. 236-246, 2007. 
[36] P. J. Sharek, L. M. Parast, K. Leong et al., "Effect of a rapid response team on hospital-wide mortality and code rates outside the ICU in a Children's Hospital," Journal of the American Medical Association, vol. 298, no. 19, pp. 2267-2274, 2007.

[37] J. Tibballs and S. Kinney, "Reduction of hospital mortality and of preventable cardiac arrest and death on introduction of a pediatric medical emergency team," Pediatric Critical Care Medicine, vol. 10, no. 3, pp. 306-312, 2009.

[38] C. P. Bonafide, A. R. Localio, K. E. Roberts, V. M. Nadkarni, C. M. Weirich, and R. Keren, "Impact of rapid response system implementation on critical deterioration events in children," JAMA Pediatrics, vol. 168, no. 1, pp. 25-33, 2014.

[39] P. S. Chan, R. Jain, B. K. Nallmothu, R. A. Berg, and C. Sasson, "Rapid response teams: a systematic review and meta-analysis," Archives of Internal Medicine, vol. 170, no. 1, pp. 18-26, 2010.

[40] A. Kotsakis, A.-T. Lobos, C. Parshuram et al., "Implementation of a multicenter rapid response system in pediatric academic hospitals is effective," Pediatrics, vol. 128, no. 1, pp. 72-78, 2011.

[41] L. J. Knight, J. M. Gabhart, K. S. Earnest, K. M. Leong, A. Anglemyer, and D. Franzon, "Improving code team performance and survival outcomes: implementation of pediatric resuscitation team training," Critical Care Medicine, vol. 42, no. 2, pp. 243251, 2014.

[42] M. E. Kleinman, L. Chameides, S. M. Schexnayder et al., "Part 14: pediatric advanced life support: 2010 American Heart Association Guidelines for Cardiopulmonary Resuscitation and Emergency Cardiovascular Care," Circulation, vol. 122, no. 3, pp. S876-S908, 2010.

[43] E. Rivers, B. Nguyen, S. Havstad et al., "Early goal-directed therapy in the treatment of severe sepsis and septic shock," The New England Journal of Medicine, vol. 345, no. 19, pp. 1368-1377, 2001.

[44] D. Rixen and J. H. Siegel, "Bench-to-bedside review: oxygen debt and its metabolic correlates as quantifiers of the severity of hemorrhagic and posttraumatic shock," Critical Care, vol. 9, no. 5, pp. 441-453, 2005.

[45] G. M. Hoffman, N. S. Ghanayem, and J. S. Tweddell, "Noninvasive assessment of cardiac output," Seminars in Thoracic and Cardiovascular Surgery, vol. 8, pp. 12-21, 2005.

[46] C. F. de Oliveira, D. S. F. de Oliveira, A. F. C. Gottschald et al., "ACCM/PALS haemodynamic support guidelines for paediatric septic shock: an outcomes comparison with and without monitoring central venous oxygen saturation," Intensive Care Medicine, vol. 34, no. 6, pp. 1065-1075, 2008.

[47] N. S. Ghanayem, G. Wernovsky, and G. M. Hoffman, "Nearinfrared spectroscopy as a hemodynamic monitor in critical illness," Pediatric Critical Care Medicine, vol. 12, no. 4, pp. S27S32, 2011.

[48] N. P. Bernal, G. M. Hoffman, N. S. Ghanayem, and M. J. Arca, "Cerebral and somatic near-infrared spectroscopy in normal newborns," Journal of Pediatric Surgery, vol. 45, no. 6, pp. 13061310, 2010.

[49] G. M. Hoffman, N. S. Ghanayem, E. A. Stuth, R. J. Berens, and J. S. Tweddell, "NIRS-derived somatic and cerebral saturation difference provides non-invasive real-time hemodynamic assessment of cardiogenic shock and risk of anaerobic metabolism," Anesthesiology, vol. 99, Article ID A1448, 2004, http://www.asaabstracts.com/strands/asaabstracts/abstract.htm ?year $=2004$ \&index $=16$ \&absnum $=2206$.

[50] G. M. Hoffman, N. S. Ghanayem, R. J. Berens, M. C. Scanlon, and C. G. Weigle, "Reduction in critical indicators of shock by routine use of two-site NIRS in pediatric ICU patients," Anesthesiology, vol. 106, p. A803, 2006, http://www.asaabstracts .com/strands/asaabstracts/abstract.htm?year $=2006 \&$ index $=6$ \&absnum $=1239$.

[51] G. M. Hoffman, N. S. Ghanayem, K. A. Mussatto, R. J. Berens, and J. S. Tweddell, "Postoperative two-site NIRS predicts complications and mortality after stage 1 palliation of HLHS," Anesthesiology, vol. 107, article A234, 2007, http://www.asaabstracts.com/strands/asaabstracts/abstract.htm?year=2007\&index $=16 \&$ absnum $=1585$.

[52] S. B. Chakravarti, A. J. C. Mittnacht, J. C. Katz, K. Nguyen, U. Joashi, and S. Srivastava, "Multisite near-infrared spectroscopy predicts elevated blood lactate level in children after cardiac surgery," Journal of Cardiothoracic and Vascular Anesthesia, vol. 23, no. 5, pp. 663-667, 2009.

[53] M. D. Berg, S. M. Schexnayder, L. Chameides et al., " Part 13: pediatric basic life support: 2010 american heart association guidelines for cardiopulmonary resuscitation and emergency cardiovascular care," Circulation, vol. 122, no. 3, supplement 3, pp. S862-S875, 2010.

[54] K. B. Kern, G. A. Ewy, W. D. Voorhees, C. F. Babbs, and W. A. Tacker, "Myocardial perfusion pressure: a predictor of 24-hour survival during prolonged cardiac arrest in dogs," Resuscitation, vol. 16, no. 4, pp. 241-250, 1988.

[55] N. A. Paradis, G. B. Martin, E. P. Rivers et al., "Coronary perfusion pressure and the return of spontaneous circulation in human cardiopulmonary resuscitation," The Journal of the American Medical Association, vol. 263, no. 8, pp. 1106-1113, 1990.

[56] T. Kitamura, T. Iwami, T. Kawamura et al., "Conventional and chest-compression-only cardiopulmonary resuscitation by bystanders for children who have out-of-hospital cardiac arrests: a prospective, nationwide, population-based cohort study," The Lancet, vol. 375, no. 9723, pp. 1347-1354, 2010.

[57] R. A. Berg, R. W. Hilwig, K. B. Kern, I. Babar, and G. A. Ewy, "Simulated mouth-to-mouth ventilation and chest compressions (bystander cardiopulmonary resuscitation) improves outcome in a swine model of prehospital pediatric asphyxial cardiac arrest," Critical Care Medicine, vol. 27, no. 9, pp. 1893 $1899,1999$.

[58] R. A. Berg, R. W. Hilwig, K. B. Kern, and G. A. Ewy, "'Bystander' chest compressions and assisted ventilation independently improve outcome from piglet asphyxial pulseless 'cardiac arrest"', Circulation, vol. 101, no. 14, pp. 1743-1748, 2000.

[59] G. A. Ewy, M. Zuercher, R. W. Hilwig et al., "Improved neurological outcome with continuous chest compressions compared with 30:2 compressions-to-ventilations cardiopulmonary resuscitation in a realistic swine model of out-of-hospital cardiac arrest," Circulation, vol. 116, no. 22, pp. 2525-2530, 2007.

[60] J. M. Iglesias, J. López-Herce, J. Urbano, M. J. Solana, S. Mencía, and J. del Castillo, "Chest compressions versus ventilation plus chest compressions in a pediatric asphyxial cardiac arrest animal model," Intensive Care Medicine, vol. 36, no. 4, pp. 712716, 2010.

[61] The American Heart Association in Collaboration with the International Liaison Committee on Resuscitation, "2005 American Heart Association Guidelines for Cardiopulmonary Resuscitation and Emergency Cardiovascular Care," Circulation, vol. 112, pp. IV-1-IV-5, 2005. 
[62] D. Yannopoulos, T. P. Aufderheide, A. Gabrielli et al., "Clinical and hemodynamic comparison of 15:2 and 30:2 compressionto- ventilation ratios for cardiopulmonary resuscitation," Critical Care Medicine, vol. 34, no. 5, pp. 1444-1449, 2006.

[63] R. M. Sutton, B. French, A. Nishisaki et al., "American Heart Association cardiopulmonary resuscitation quality targets are associated with improved arterial blood pressure during pediatric cardiac arrest," Resuscitation, vol. 84, no. 2, pp. 168-172, 2013.

[64] D. Niles, R. M. Sutton, A. Donoghue et al., “"Rolling Refreshers”: a novel approach to maintain CPR psychomotor skill competence," Resuscitation, vol. 80, no. 8, pp. 909-912, 2009.

[65] E. P. Rivers, J. Wortsman, M. Y. Rady, H. C. Blake, F. T. McGeorge, and N. M. Buderer, "The effect of the total cumulative epinephrine dose administered during human CPR on hemodynamic, oxygen transport, and utilization variables in the postresuscitation period," Chest, vol. 106, no. 5, pp. 14991507, 1994.

[66] R. A. Berg, C. W. Otto, K. B. Kern et al., "High-dose epinephrine results in greater early mortality after resuscitation from prolonged cardiac arrest in pigs: a prospective, randomized study," Critical Care Medicine, vol. 22, no. 2, pp. 282-290, 1994.

[67] R. A. Berg, C. W. Otto, K. B. Kern et al., "A randomized, blinded trial of high-dose epinephrine versus standard-dose epinephrine in a swine model of pediatric asphyxial cardiac arrest," Critical Care Medicine, vol. 24, no. 10, pp. 1695-1700, 1996.

[68] M. B. M. Perondi, A. G. Reis, E. F. Paiva, V. M. Nadkarni, and R. A. Berg, "A comparison of high-dose and standard-dose epinephrine in children with cardiac arrest," The New England Journal of Medicine, vol. 350, no. 17, pp. 1722-1730, 2004.

[69] R. A. Dieckmann and R. Vardis, "High-dose epinephrine in pediatric out-of-hospital cardiopulmonary arrest," Pediatrics, vol. 95, no. 6, pp. 901-913, 1995.

[70] T. C. Carpenter and K. R. Stenmark, "High-dose epinephrine is not superior to standard-dose epinephrine in pediatric inhospital cardiopulmonary arrest," Pediatrics, vol. 99, no. 3, pp. 403-408, 1997.

[71] S. A. Warren, E. Huszti, S. M. Bradley et al., "Adrenaline (epinephrine) dosing period and survival after in-hospital cardiac arrest: a retrospective review of prospectively collected data," Resuscitation, vol. 85, no. 3, pp. 350-358, 2014.

[72] "2005 American Heart Association guidelines for cardiopulmonary resuscitation and emergency cardiovascular care. Part 12 pediatric advanced life support," Circulation, vol. 112, pp. 167$187,2005$.

[73] V. Srinivasan, M. C. Morris, M. A. Helfaer, R. A. Berg, and V. M. Nadkarni, "Calcium use during in-hospital pediatric cardiopulmonary resuscitation: a report from the national registry of cardiopulmonary resuscitation," Pediatrics, vol. 121, no. 5, pp. el144-e1151, 2008.

[74] H. J. Dalton, R. D. Siewers, B. P. Fuhrman et al., "Extracorporeal membrane oxygenation for cardiac rescue in children with severe myocardial dysfunction," Critical Care Medicine, vol. 21, no. 7, pp. 1020-1028, 1993.

[75] J. W. Turek, N. D. Andersen, D. S. Lawson et al., "Outcomes before and after implementation of a pediatric rapid-response extracorporeal membrane oxygenation program," Annals of Thoracic Surgery, vol. 95, no. 6, pp. 2140-2147, 2013.

[76] M. C. Morris, G. Wernovsky, and V. M. Nadkarni, "Survival outcomes after extracorporeal cardiopulmonary resuscitation instituted during active chest compressions following refractory in-hospital pediatric cardiac arrest," Pediatric Critical Care Medicine, vol. 5, no. 5, pp. 440-446, 2004.

[77] B. Alsoufi, O. O. Al-Radi, R. I. Nazer et al., "Survival outcomes after rescue extracorporeal cardiopulmonary resuscitation in pediatric patients with refractory cardiac arrest," Journal of Thoracic and Cardiovascular Surgery, vol. 134, no. 4, pp. 952e2959.e2, 2007.

[78] T. T. Raymond, C. B. Cunnyngham, M. T. Thompson et al., "Outcomes among neonates, infants, and children after extracorporeal cardiopulmonary resuscitation for refractory inhospital pediatric cardiac arrest: a report from the National Registry of Cardiopulmonary Resuscitation," Pediatric Critical Care Medicine, vol. 11, no. 3, pp. 362-371, 2010.

[79] M. J. Wolf, K. R. Kanter, P. M. Kirshbom, B. E. Kogon, and S. F. Wagoner, "Extracorporeal cardiopulmonary resuscitation for pediatric cardiac patients," Annals of Thoracic Surgery, vol. 94, no. 3, pp. 874-880, 2012.

[80] K. H. Polderman, "Mechanisms of action, physiological effects, and complications of hypothermia," Critical Care Medicine, vol. 37, no. 7, pp. S186-S202, 2009.

[81] V. A. Negovsky, "Postresuscitation disease," Critical Care Medicine, vol. 16, no. 10, pp. 942-946, 1988.

[82] S. E. Jacobs, R. Hunt, W. O. Tarnow-Mordi, T. E. Inder, and P. G. Davis, "Cooling for newborns with hypoxic ischaemic encephalopathy," The Cochrane Database of Systematic Reviews, no. 4, Article ID CD003311, 2007.

[83] S. A. Bernard, T. W. Gray, M. D. Buist et al., "Treatment of comatose survivors of out-of-hospital cardiac arrest with induced hypothermia," The New England Journal of Medicine, vol. 346, no. 8, pp. 557-563, 2002.

[84] The Hypothermia after Cardiac Arrest Study Group, "Mild therapeutic hypothermia to improve the neurologic outcome after cardiac arrest," The New England Journal of Medicine, vol. 346, no. 22, pp. 1756-1756, 2002.

[85] S. Bernard, "Hypothermia after cardiac arrest: expanding the therapeutic scope," Critical Care Medicine, vol. 37, no. 7, pp. S227-S233, 2009.

[86] S. A. Bernard, K. Smith, P. Cameron et al., "Induction of therapeutic hypothermia by paramedics after resuscitation from outof-hospital ventricular fibrillation cardiac arrest: a randomized controlled trial," Circulation, vol. 122, no. 7, pp. 737-742, 2010.

[87] J. Arrich, M. Holzer, C. Havel, M. Müllner, and H. Herkner, "Hypothermia for neuroprotection in adults after cardiopulmonary resuscitation," Cochrane Database of Systematic Reviews, vol. 9, Article ID CD004128, 2012.

[88] M. Holzer, "Targeted temperature management for comatose survivors of cardiac arrest," The New England Journal of Medicine, vol. 363, no. 13, pp. 1256-1264, 2010.

[89] B. Scholefiled, H. Duncan, and P. Davies, "Hypothermia for neuroprotection in children after cardiopulmonary arrest," Cochrane Database of Systematic Reviews, vol. 2, Article ID CD009442, 2013.

[90] B. Suffoletto, M. A. Peberdy, T. van der Hoek, and C. Callaway, "Body temperature changes are associated with outcomes following in-hospital cardiac arrest and return of spontaneous circulation," Resuscitation, vol. 80, no. 12, pp. 1365-1370, 2009.

[91] R. W. Hickey, P. M. Kochanek, H. Ferimer, S. H. Graham, and P. Safar, "Hypothermia and hyperthermia in children after resuscitation from cardiac arrest," Pediatrics, vol. 106, no. 1, part 1, pp. 118-122, 2000. 
[92] R. W. Hickey, P. M. Kochanek, H. Ferimer, H. L. Alexander, R. H. Garman, and S. H. Graham, "Induced hyperthermia exacerbates neurologic neuronal histologic damage after asphyxial cardiac arrest in rats," Critical Care Medicine, vol. 31, no. 2, pp. 531-535, 2003.

[93] M. M. Bembea, V. M. Nadkarni, M. Diener-West et al., “Temperature patterns in the early postresuscitation period after pediatric in hospital cardiac arrest," Pediatric Critical Care Medicine, vol. 11, no. 6, pp. 723-730, 2010.

[94] N. S. Abend, A. Topjian, R. Ichord et al., "Electroencephalographic monitoring during hypothermia after pediatric cardiac arrest," Neurology, vol. 72, no. 22, pp. 1931-1940, 2009.

[95] A. A. Topjian, A. M. Gutierrez-Colina, S. M. Sanchez et al., "Electrographic status epilepticus is associated with mortality and worse short-term outcome in critically III children," Critical Care Medicine, vol. 41, no. 1, pp. 215-223, 2013.

[96] S. K. Kessler, A. A. Topjian, A. M. Gutierrez-Colina et al., "Short-term outcome prediction by electroencephalographic features in children treated with therapeutic hypothermia after cardiac arrest," Neurocritical Care, vol. 14, no. 1, pp. 37-43, 2011. 


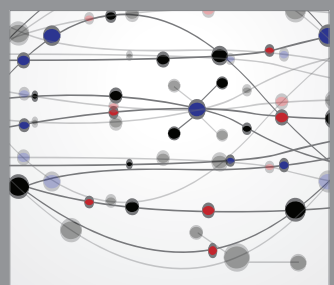

The Scientific World Journal
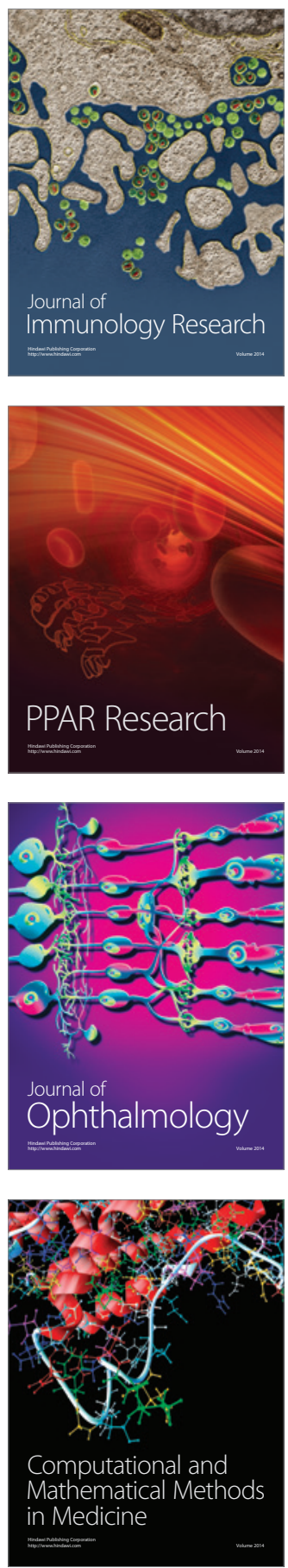

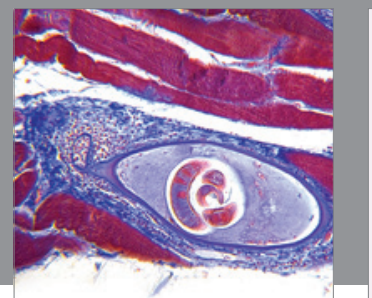

Gastroenterology

Research and Practice
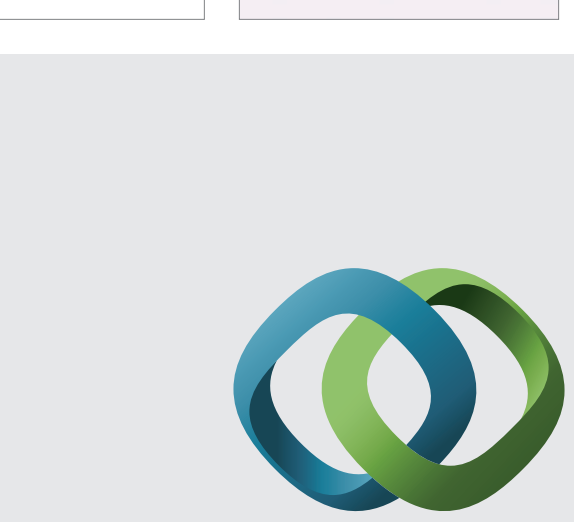

\section{Hindawi}

Submit your manuscripts at

http://www.hindawi.com
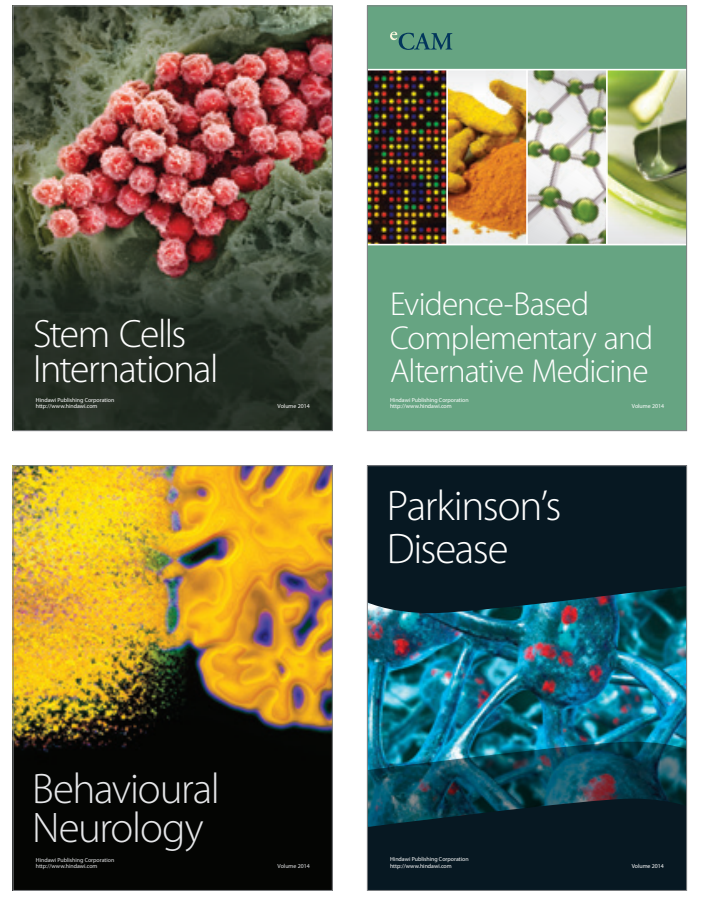
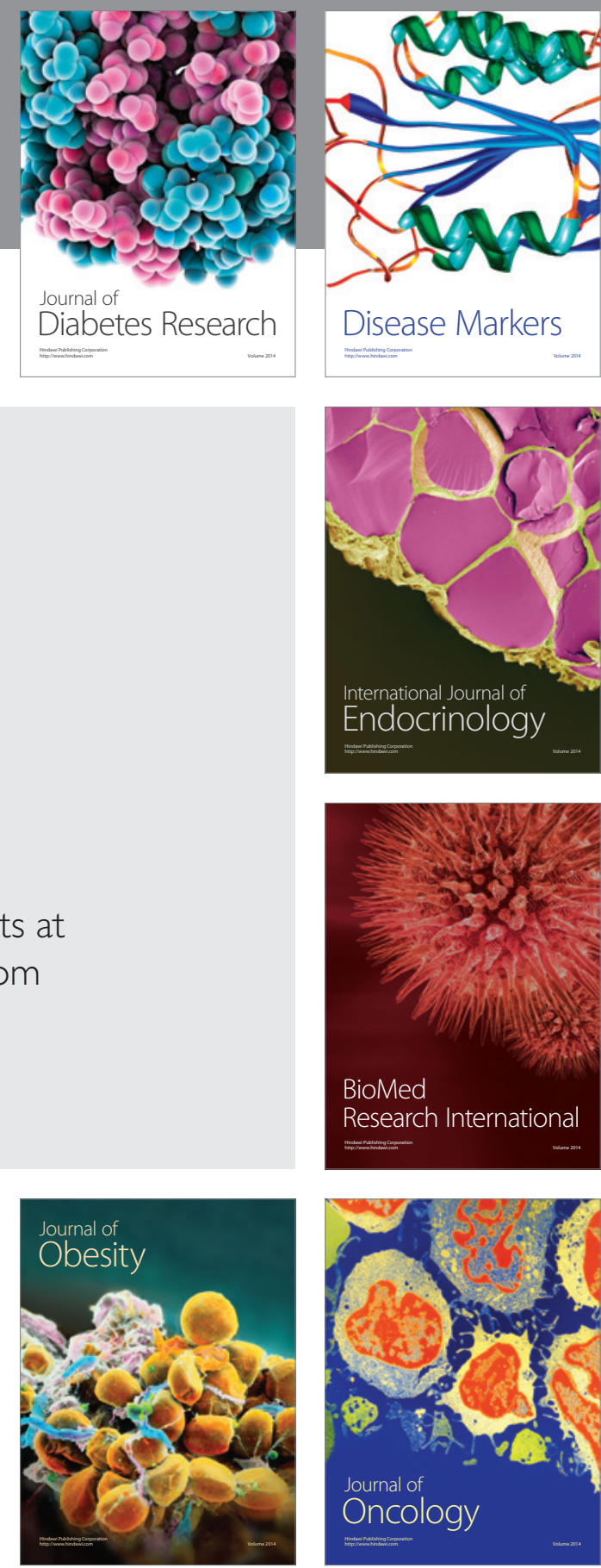

Disease Markers
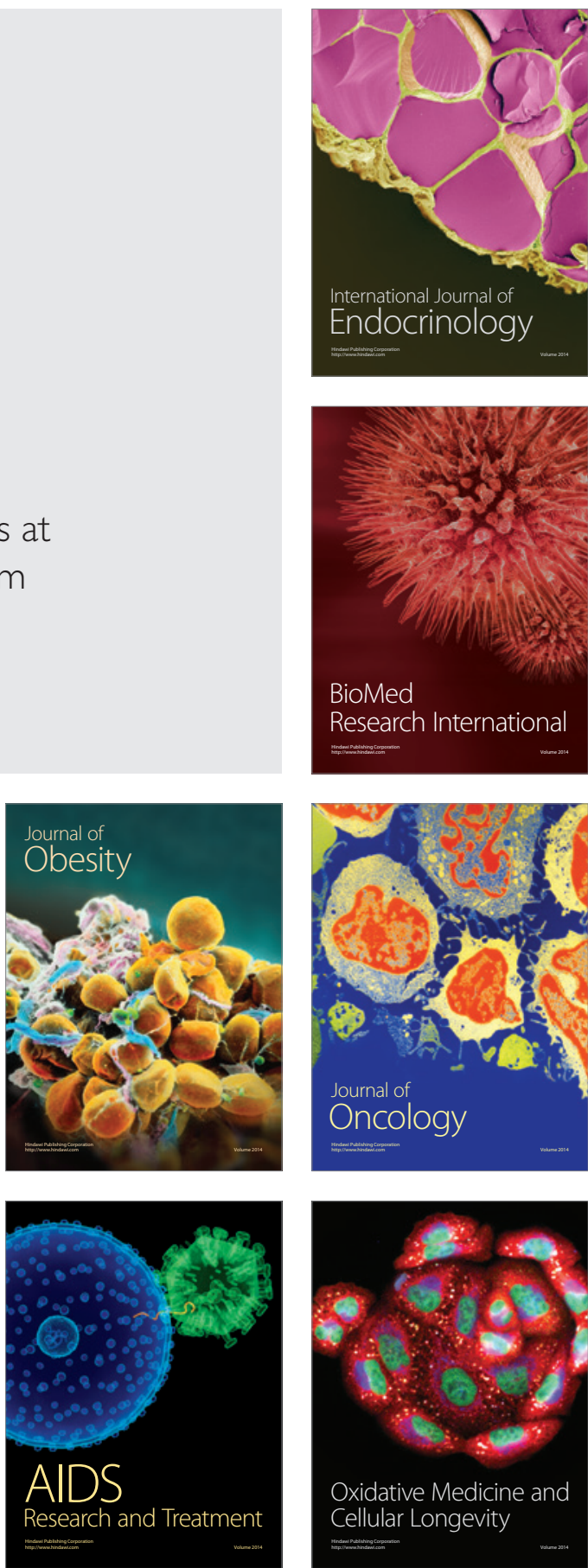